Вопросы журналистики. 2018. № 4

УДК 070.15

DOI: $10.17223 / 26188422 / 4 / 4$

\title{
Б.Я. Мисонжников
}

\section{ОБРАЗ РОССИИ В ЗАПАДНОМ МЕДИЙНОМ ДИСКУРСЕ}

В статье рассматриваются механизмы формирования образа современной России в западном медийном дискурсе, представленном ведущими качественными газетами - The New York Times u Frankfurter Allgemeine Zeitung. Koppeспонденты этих аналитических изданий выступают с позиций политической пропаганды и отходят от канонов независимой и объективной прессы. Систему аргументачии они зачастую подменяют суждениями, не подкрепленными фактами. По сути, используют методики «разрушения» образа, чем наносят ущерб гуманитарным нормам и критериям журналистики.

Ключевые слова: медийный дискурс, образ России, качественная пресса, газеты The New York Times и Frankfurter Allgemeine Zeitung, пропаганда.

Образ какой-либо страны формируется под влиянием многих факторов, и один из самых действенных - представление его в медийном пространстве. Причем в пространстве не в пассивном, а, наоборот, в предельно актуализированном, обретающем свойства дискурса, захватывающего реципиента напряженной драматургией и изобретательной сюжетикой. Образ страны - это своеобразный артефакт, в значительной мере порождение воли автора, порой пристрастного, а зачастую предвзятого и тенденциозного. Совершается реверсивный процесс: с одной стороны, автор, во многом исходя из собственных интересов, участвует в создании медиапродукта, влияющего на мировосприятие и выбор позиции аудиторией, а с другой стороны, социум и конкретная аудитория, являющаяся иногда исключительно активной частью социума, оказывают мощное влияние на автора.

Представители истеблишмента, прежде всего политического и финансового, составляют самую влиятельную часть аудитории качественной прессы, и именно они могут радикально воздействовать на редакционные коллективы, требуя соответствующей релевантности в освещении событий. Они фактически в состоянии принуждать автора к поступкам, порой предосудительным, а то и безнравственным и постыдным. Нередко случается так, что автор старается угодить тем, кто 
оплачивает его работу, и вследствие этого преднамеренно искажает факты, допускает диффамацию. Он включает механизм самоконтроля, порой интуитивно и безотчетно, понимая вместе с тем, что от того, какую позицию он занимает, зависит его карьерный успех и в конце концов уровень благосостояния.

Журналисту, освещающему политические события в условиях международной напряженности, трудно быть объективным. Один из немногих достойных уважения примеров - позиция Уолтера Липпмана, который в условиях «холодной войны» придерживался взвешенных суждений и стремился к непредвзятому анализу происходящего. Вот мнение В.О. Печатнова об американском журналисте: «Прежде всего, сами источники советского поведения он видел не столько в идеологии, сколько в рациональных стратегических интересах великой державы, обусловленных ее историей, географическим положением и ресурсами. Русская армия, напоминал Липпман, оказалась в сердце Европы не в силу идеологического мессианства, а в результате агрессии Гитлера и нежелания Запада взять на себя главное бремя войны с ним на Европейском континенте. ...Липпман... умудрился занять независимую позицию, в целом трезво оценивая характер "советского вызова" и не впадая в кликушество, свойственное большинству его собратьев по перу, видевших тогда спасение Америки только в массированном перевооружении» [1. С. 219, 269].

Еще один пример, поистине уникальный и беспрецедентный, выполнения журналистского долга в тяжелейших условиях господствующей преступной идеологии и политической агрессии - это сотрудничество Рихарда Зорге с редакцией влиятельной нацистской газеты Frankfurter Zeitung, фактически предшественницей современной Frankfurter Allgemeine Zeitung. Будучи одним из самых известных публицистов в Германии и собственным корреспондентом этой газеты - причем для советского разведчика это не было профессиональным «прикрытием», а было, скорее, осуществлением творческого призвания, - он не опубликовал ни одного материала, который не отвечал бы его убеждениям и противоречил бы его творческой воле. Журналистская позиция Зорге всегда оставалась безупречной.

К сожалению, мир возвращается к ситуации жесткого противостояния России и Запада. Уже четко обозначился системный социальнополитический разлом, который напрямую и очень глубоко затронул не только экономическую, военную, научно-производственную, куль- 
турно-цивилизационную, но и гуманитарную области: массы людей оказались вовлеченными в противостояние между Западом и Россией, и мир опять оказался на пороге возможной катастрофы. Сейчас нет противоборства идеологий, как это было в годы «холодной войны», превалируют, прежде всего, национальные прагматические интересы. Однако в годы идеологического противостояния противники серьезно изучали друг друга, знали слабые и сильные места, умели договариваться и соблюдали в своих действиях определенные негласные правила. Кроме того, конфронтация носила блоковый характер: она осуществлялась в рамках двух гигантских военно-политических объединений.

В настоящее время даже военный блок НАТО не выдерживает диалектически неизбежного воздействия энтропийных факторов, хотя и предпринимаются попытки - в настоящее время все более активные - восстановить его былое могущество. Система во многом устарела и явно переживает стадию деконструкции, что, однако, отнюдь не делает ее менее опасной. Среди государств, входящих в этот блок, то и дело возникают конфликтные ситуации. Во всяком случае, разногласия порой приобретают системный характер, что выразилось, в частности, в санкционных угрозах США даже по адресу стран, входящих в этот военный блок.

То есть модель геополитического развития обрела черты нестабильности, хаотичности и непредсказуемости, что непосредственно сказывается и на процессах медиатизации: масс-медиа сегодня во всем мире отличаются значительной непоследовательностью, субъективностью и ангажированностью, причем эти качества сочетаются зачастую с агрессивностью, политическим менасивом и другими проявлениями неэтикетного и даже враждебного речевого поведения по отношению к оппонентам. В то же время необходимо учитывать масштабные технологические изменения, которые претерпели медийные комплексы: благодаря мультимедийным системам возможности масс-медиа небывало возросли, превратив их в глобальную мощную пропагандистскую машинерию. Да и газетно-журнальный медийный сегмент вопреки некоторым некомпетентным суждениям продолжает развиваться и совершенствоваться, хотя и в переструктурированном виде.

Объектом особого внимания практически всех мировых массмедиа стала Россия, которая интерпретируется многоаспектно, оцениваются ее социально-политические, экономические, культурные сто- 
роны. Делается это зачастую преднамеренно негативно, превратно истолковываются даже казалось бы очевидные факты. Очернить все, что совершают россияне, стало едва ли не основным трендом современной медийной политики. Масс-медиа, прежде всего западные, превращаются в инструмент достижения корыстных интересов и отступают от императивов объективности и гуманизма, что должно характеризовать журналистику как социальный институт.

Целью западной медийной системы, которая фактически уже давно превратилась в средство пропаганды, стало создание резко негативного образа России. В ней видят не просто конкурента в социально-политической и экономической областях, но уже, по сути, глобального противника. По мере того, как обретают впечатляющие масштабы самостоятельность и независимость России, возрастает военно-промышленный потенциал, а также становится все более заметным ее международное влияние, усиливается активность западной медийной системы, направленная на преднамеренную демонизацию России, представление ее как дикой, нецивилизованной страны с непредсказуемой и опасной политикой. Подобные действия западных масс-медиа формируют неприглядный, отталкивающий образ России, что отрицательно сказывается на ее международной репутации и наносит прямой ущерб национальной безопасности. К этому надо прибавить еще и многочисленные публикации в отечественных СМИ и в социальных сетях, содержащие не только необъективную критику отдельных сторон российской политики, но и злобные, оскорбительные высказывания явно клеветнического характера.

Примечательно, что и качественные газеты, самые влиятельные в мире издания, перестали непредвзято оценивать ситуацию, а во многих исходных концептуальных своих устремлениях перешли на платформу политической аксиоматики: не опираясь на эмпирические данные и без логического анализа, используют готовые оценочные клише с негативной коннотацией. Уровень влияния этих изданий носит глобальный характер, и в них представлена преимущественно авторская журналистика, что позволяет идентифицировать профессиональные действия субъектов медийного процесса. Как правило, это неплохо подготовленные и даже вышколенные в технологическом отношении сотрудники политических редакций, выступления которых даже в мелочах не противоречат общей политической платформе владельцев медиа. 
В то же время надо учитывать, что западная система масс-медиа, несмотря на отдельные внутренние противоречия и стремление к самостоятельным суждениям, идеологически и субординационно выстроена достаточно четко: тон задают обычно ведущие качественные газеты. В Европе это - Financial Times, Frankfurter Allgemeine Zeitung, Neue Zürcher Zeitung, а в США - The New York Times. Если учитывать, что эти печатные издания располагают также собственными сетевыми порталами, воссоздающими те публикации, которые появились на бумажных носителях и которые, таким образом, доступны миллионам читателей на всем земном шаре, то несложно определить уровень влияния данного совокупного мультимедийного комплекса. Каждая публикация автора названных выше изданий обретает эффект многократного повторения и реализует определяющую и направляющую функцию в аксиологическом плане - политическом, социальном, экономическом и даже культурном. Речь идет не только о выборе основных идеологических направлений, воссоздающих западный медийный мейнстрим, но значение обретает даже тональность высказываний, умение что-то замалчивать, а что-то, наоборот, чрезмерно активно актуализировать.

И еще один важный политический нюанс: медийный истеблишмент выдвигает журналистов, не лишенных достаточно высокого профессионального уровня, амбициозных и в то же время покладистых, не претендующих на самостоятельность суждений и высказывающихся явно в русле текущей национальной политики, какой бы она ни была. Редакция одной из самых влиятельных в мире качественных газет The New York Times на должность репортера по вопросам национальной безопасности, освещающего, в частности, деятельность разведслужб, пригласила в 2018 г. в вашингтонское бюро выпускника Гарвардского университета Джулиана Барнса, который до этого работал в брюссельском и вашингтонском бюро The Wall Street Journal, а еще ранее сотрудничал с Los Angeles Times, Arkansas Democrat-Gazette и U.S. News \& World Report.

Немногим раньше, и также по направлению национальной безопасности, в вашингтонском бюро The New York Times начал работать Мэттью Розенберг, который окончил бакалаврское отделение государственного университета Макгилла в Квебеке. До того как стать репортером по вопросам национальной безопасности в редакции газеты The New York Times, Розенберг был собственным корреспондентом 
этой газеты по Азии, Африке и Среднему Востоку и в 2018 г. был удостоен Пулитцеровской премии за освещение избирательной кампании Дональда Трампа и его отношений с Россией. Еще раньше Розенберг работал в редакциях газеты The Wall Street Journal и международного агентства информации и новостей The Associated Press.

Одна из самых заметных публикаций Барнса и Розенберга «Кремлевские источники идут тихо, во тьме покидая ЦРУ и оставляя информацию о планах Путина на промежуточные выборы» [2]. Публикация была посвящена промежуточным американским выборам и, конечно, в соответствии с должностной спецификой авторов освещалась, прежде всего, в аспекте национальной безопасности США. Главная угроза для независимого проведения выборов, как можно судить из контекста материала, исходит от России. Уже в самом начале аналитической корреспонденции - пожалуй, именно так можно определить жанр публикации - авторы заявляют о том, что еще два года тому назад «американские разведывательные органы срочно и с полной уверенностью предупредили о намерении России сорвать американские президентские выборы, и подробнейшая информация об этом, а также оценка операции появилась в значительной степени благодаря осведомителям, близким к президенту Путину и кремлевским кругам, которые предоставили важные детали». Необходимо отметить, что текст и заголовка материала, и первого абзаца содержит явные признаки провокативного дискурса: сообщается о наличии у американских спецслужб агентурной сети в непосредственной близости к руководству России. Заявление голословно, как, впрочем, и вся публикация, но оно обладает довольно сильным потенциалом прагматического воздействия.

Отсутствие конкретных аргументов авторы пытаются компенсировать повышением эмоционального тона, патетикой борцов с несправедливостью и неоправданно сложными и даже замысловатыми речевыми конструкциями с избыточной модальностью. Барнс и Розенберг как бы стремятся к применению приема аподиктической аргументации, но получается только ее видимость, поскольку данная аргументация предполагает использование точных, практически научных фактов и жесткой логичности текстуализации. Этого в публикации нет. Материал строится на гипотетических суждениях с элементами хорроризации и подается как констатация свершившегося: «должностные лица не считают, что источники были скомпрометированы 
или убиты»; «условия более агрессивной деятельности контрразведки со стороны Москвы»; «попытки убить шпионов, как это было связано с отравлением в марте в Великобритании бывшего офицера разведки России»; «использовался редкий российский агент нервнопаралитического действия» и т.д.

Барнс и Розенберг, вместе с тем, чтобы придать публикации хотя бы некоторый эффект достоверности, ссылаются на своих ньюсмейкеров - неких «должностных лиц», которые стремились «защитить методы сбора информации в России» и «говорили на условиях анонимности, поскольку не были уполномочены раскрывать секретную информацию», а «пресс-секретарь ЦРУ отказался от комментариев». И следующее немаловажное заключение авторов: «Соединенные Штаты используют различные формы разведки, включая перехваченные коммуникации и проникновение в компьютерные сети».

Из текста корреспонденции Барнса и Розенберга возникает образ России как агрессивного, тоталитарного и опасного государства, которое в своей политике активно использует спецслужбы, готовые с целью реализации захватнических планов на любые действия, вплоть до убийства. Неприглядный образ страны, который формируется при помощи вербального текста, а в сетевом варианте, кстати сказать, дополняется большим количеством гиперссылок, приобретает особую негативную коннотацию вследствие иконического материала: с заголовком корреспонденции коррелирует мрачная фотография, на которой представлена фигура солдата на фоне кремлевских башен, и особо зловещий эффект создает затянутое тучами небо. Примечательно, что всей публикации в целом присуща пристрастность и экспрессивность, что, в принципе, не должно соотноситься с формой презентации материала качественной газетой. Нельзя не признать справедливым мнение о том, что «на современном этапе лингвистических знаний экспрессивность рассматривается как результат взаимодействия эмотивности, оценочности, образности, интенсивности, стилистической маркированности» [3. С. 131]. Эти качества, присущие рассматриваемой публикации, вызывают удивление и ощущение определенной субъективности и даже предвзятости авторской позиции, выраженной, по сути, в маниакально-нервозной форме. Это напоминает некую «игру в шпионов» и принципиально идет вразрез с типологической концептуальностью качественного издания, приоритет которого - строго взвешенная и максимально дискурсивная оценка событий, 
консерватизм во взгляде на происходящее, уважение к фактам и осторожное отношение к домыслам и подозрениям. Экспрессивность уместна, прежде всего, в бульварной прессе.

В европейском медийном дискурсе решающую роль играют издания стран, входящих в Североатлантический альянс и в целом выстраивающих свою политику в интересах Соединенных Штатов. Этим обусловлен вектор их медийной политики вообще и в отношении к России в частности. Так, довольно быстро и активно подключилась к антироссийской общей риторике Frankfurter Allgemeine Zeitung, одна из самых влиятельных в мире газет. Среди ее ведущих корреспондентов - имеющий магистерскую степень Петер Карстенс, который в Вене, Париже и Берлине изучал историю, политику и философию, работал в канцелярии столичного сената, а в сентябре 1994 г. пришел в информационную редакцию Frankfurter Allgemeine Zeitung, в которой теперь освещает политические события. О Карстенсе стоит сказать не только потому, что он имеет неплохую академическую научную подготовку и опыт репортерской работы, что позволило ему встать в ряд ведущих немецких журналистов, но и выступил автором довольно резонансной публикации «Убедительное сдерживание», репортаже, рассказывающем о крупнейших за последние 30 лет учениях НАТО в Норвегии [4]. С одной стороны, западные политики говорили о том, что эти учения не направлены против России, а с другой стороны, главнокомандующий Объединенными силами НАТО в Европе американский генерал Кертис Скапаротти прямо заявил, что «альянс покажет России свои способности по защите суверенной страны». Об этом сообщал и автор репортажа: солдаты отрабатывают «в тяжелых климатических условиях быструю реакцию на агрессию со стороны Крайнего Севера. Под этим подразумевается, согласно положению вещей, Россия, пусть даже в натовских документах об этом прямо и не говорится. ...После русского нападения на Крым, позиционной войны на Восточной Украине и угрожающего жеста Москвы на границе балтийских государств ситуация постепенно меняется». То есть меняется к худшему, потому что Россия ведет себя как агрессор.

Конечно, возникает немало вопросов в отношении объективности суждений Карстенса. Хотя бы по поводу того, кто спровоцировал события, вследствие которых Крым перешел в состав России, началась война с многочисленными жертвами мирного населения на востоке 
Украины, и тем более что касается «угрожающего жеста Москвы на границе балтийских государств». Но как бы то ни было автор репортажа воссоздает достаточно четкую картину: Россия - захватчик, а страны Североатлантического альянса - поборники мира и демократии, которые призваны сдерживать этого наглого и беспринципного агрессора. Собственно, идея репортажа, его антироссийская риторика, апологетика натовского военного потенциала - это то, что соответствует западным идеологическим стандартам. Другого, пожалуй, и не следовало ожидать от сотрудника ведущей немецкой газеты. Но нельзя не обратить внимания на одну существенную деталь: Карстенс навязчиво восхваляет боевой дух и выучку солдат бундесвера, выражает даже восторг в связи с тем, что солдаты «бундесвера на удивление хорошо оснащены. Солдаты рады тому, что они, наконец, имеют возможность показать, на что способны». Романтика силы, победной энергии пронизывает всю публикацию: «в шесть часов утра можно увидеть 4000 довольных мужчин и женщин (т.е. солдат. - Б.М.)»; «через три дня на севере должны атаковать красные (условный противник. - Б.М.), и большинство этому рады, особенно те, кто из бундесвера». Слово «радость» и образованные от него лексические формы звучат неоднократно. Это очень напоминает бодрые марши солдат вермахта, отправляющихся на войну, как на веселую прогулку.

В этом отношении позиция Карстенса соответствует настроениям, которые наблюдаются в общественном сознании некоторых современных немцев, понемногу становясь, к сожалению, тревожным социальным трендом: героизация немецкого солдата, причем не только современного, но и того, кто был в вермахте. Об этом можно судить, в частности, на основе множества комментариев к фильму «Вторая мировая война: немецкий вермахт на восточном фронте». Для некоторых это - «истинные герои», «настоящие солдаты, крепкие парни», хотя, конечно, есть и другие мнения. В большей степени попытка изменить взгляд на солдат вермахта проявилась в немецком художественном фильме «Наши матери, наши отцы», герои которого - милые одухотворенные юноши, вдруг оказавшиеся на фронте, а советские солдаты - насильники и мародеры.

Фактически внедряется в сознание идея о варварстве советского солдата, создается своеобразный противовес формированию положительного образа России: силы, противостоящие ей в кровопролитной войне, исторически не столь и отдаленной, начинают выглядеть по- 
рой в позитивном и даже благородном свете. Исторические события получают новое истолкование. Это способствует разрушению положительного образа объекта, особенно если данные действия продолжительны во времени. Объект в данном случае - это та страна, против которой вели войну «бравые солдаты» Третьего рейха, и «необходимо помнить, что подобная разрушительная акция может создать амнезию на объект или событие, закодированные в образе». В итоге может иметь место «взрыв образа», и «действенность данного метода основывается на очень быстром усилении (интенсификации) ведущей субмодальности образа, так что она превышает благоразумный предел и “лопается" вместе с образом, который восстановлению не подлежит» [5. С. 147].

Безусловно, все это становится не спонтанным выпадом против какого-либо объекта, а инструментом продуманной и довольно эффективной пропаганды, направленной в данном случае против современной России. Пространством, в котором осуществляется эта пропаганда, уже стали западные качественные издания, претендующие на статус высокой журналистики. Вне всякого сомнения, они не должны выполнять подобную функцию, поскольку призваны быть средством объективного информирования, взвешенного и независимого аналитического исследования, аргументированного мнения. К сожалению, приходится констатировать, что это не так. Журналистика, превращаясь в орудие пропаганды корыстных и далеко не всегда нравственных идеалов, утрачивает свое нравственное и гуманитарное начало.

\section{Лumepamypa}

1. Печатнов В.О. Уолтер Липпман и пути Америки. М. : Междунар. отношения, 1994. $336 \mathrm{c}$.

2. Barnes J.E., Rosenberg M. Kremlin Sources Go Quiet, Leaving C.I.A. in the Dark About Putin's Plans for Midterms // The New York Times. 2018. 24 aug. URL: https://thinklab.com/julianbarnes

3. Поиепня Д.М. Образ мира в слове писателя. СПб. : Изд-во СПб. ун-та, 1997. $264 \mathrm{c}$.

4. Carstens P. Glaubwürdige Abschreckung // Frankfurter Allgemeine Zeitung. 2018. 26. Okt. URL: http://www.faz.net/aktuell/politik/ausland/nato-manoever-tridentjuncture-glaubwuerdige-abschreckung-15856692.html

5. Гримак Л., Кордобовский О. Психическая саморегуляция личности - важный элемент современной культуры // Человек вчера и сегодня: междисциплинарные исследования / отв. ред. М.С. Киселева. М. : ИФРАН, 2008. 249 с. 


\section{THE IMAGE OF RUSSIA IN WESTERN MEDIA DISCOURSE}

Voprosy zhurnalistiki - Russian Journal of Media Studies. 2018. 4, pp. 81-92.

Boris Ya. Misonzhnikov, Saint Petersburg State University (Saint Petersburg, Russian Federation). E-mail: bmiss20550@mail.ru

DOI: DOI: $10.17223 / 26188422 / 4 / 4$

Keywords: media discourse, image of Russia, high-quality press, The New York Times, Frankfurter Allgemeine Zeitung, propaganda.

One of the most effective factors in shaping the image of a country is its representation in an actualized media space, which acquires the properties of discourse. But representatives of the establishment, above all the political and financial ones, who constitute the most influential part of the audience for high-quality press, can radically influence editorial teams, demanding corresponding relevance in covering events. Journalists who deal with political issues are under all-round pressure, and it is difficult for them to be objective.

Unfortunately, the modern world is returning to the situation of a hard confrontation between Russia and the West. The systemic sociopolitical conflict, which deeply affected the economic, military, scientific production, cultural, civilizational and humanitarian areas, is already clearly defined: the masses are involved in the confrontation between the West and Russia. The goal of the western media system, which in fact has long been become a means of propaganda, is to create a negative image of Russia. They see Russia not just as a competitor in the sociopolitical and economic fields, but already, in fact, as a global adversary. As Russia becomes more independent, as its military-industrial potential increases, and its international influence becomes more and more noticeable, the activity of the western media system, aimed at a deliberate demonization of Russia, increases.

In the western mass media system, leading high-quality newspapers set the tone. In Europe, these are The Financial Times, Frankfurter Allgemeine Zeitung, Neue Zürcher Zeitung, and in the USA, The New York Times. These publications have their own web portals, which significantly increases the level of their political influence, turning them into powerful multimedia complexes.

Journalists J. E. Barnes and M. Rosenberg, who published the correspondence “Kremlin Sources Go Quiet, Leaving C.I.A. in the Dark About Putin's Plans for Midterms", dealt with national security issues in The New York Times. Journalists wrote that the main threat to the independent holding of elections in the US comes from Russia. But no conclusive evidence was given.

Quite actively involved in the anti-Russian rhetoric is the Frankfurter Allgemeine Zeitung, one of the most influential newspapers in the world. The journalist of this newspaper, P. Carstens, published a report "Convincing Deterrence" about the largest NATO exercises in Norway in the past 30 years. The report says that military exercises are directed against Russia, from which comes the threat to the Western community. At the same time, P. Carstens praises German soldiers, speaks of their excellent equipment and combat skills.

Frankfurter Allgemeine Zeitung, one of the most influential newspapers in the world, is quite actively involved in the anti-Russian rhetoric. Its journalist P. Carstens published a 
report "Convincing Deterrence" about the largest NATO exercises in Norway in the past 30 years. The report says that military exercises are directed against Russia, from which comes the threat to the Western community. At the same time, P. Carstens praises German soldiers, speaks of their excellent equipment and combat skills.

All this is not a spontaneous attack on Russia, but a thoughtful and rather effective propaganda. There is every reason for stating that western high-quality newspapers are no longer a means of objective analytics and independent opinions, but more and more often a means of propaganda. Journalism, turning into a tool of propaganda of selfserving and not always moral ideals, loses its humanitarian principles.

\section{References}

1. Pechatnov, V.O. (1994) Uolter Lippman i puti Ameriki [Walter Lippman and the ways of America]. Moscow: Mezhdunar. otnosheniya.

2. Barnes, J.E. \& Rosenberg, M. (2018) Kremlin Sources Go Quiet, Leaving C.I.A. in the Dark About Putin's Plans for Midterms. The New York Times. 24 Aug. [Online] Available from: https://thinklab.com/julianbarnes.

3. Potsepnya, D.M. (1997) Obraz mira v slove pisatelya [The image of the world in the writer's word]. St. Petersburg: St. Petersburg State University.

4. Carstens, P. (2018) Glaubwürdige Abschreckung [Convincing Deterrence]. Frankfurter Allgemeine Zeitung. 26 Oct. [Online] Available from: http://www.faz.net/ aktuell/politik/ausland/nato-manoever-trident-juncture-glaubwuerdige-abschreckung15856692.html.

5. Grimak, L. \& Kordobovskiy, O. (2008) Psikhicheskaya samoregulyatsiya lichnosti - vazhnyy element sovremennoy kul'tury [Psychic self-regulation of personality as an important element of modern culture]. In: Kiseleva, M.S. (ed.) Chelovek vchera $i$ segodnya: mezhdistsiplinarnyye issledovaniya [Man yesterday and today: interdisciplinary research]. Moscow: IPh RAS. 